\title{
Olhar sobre as margens: Uma leitura de Pingentes, de João Antônio e Zero grau de Libra, de Caio Fernando Abreu
}

Flávia Merighi Valenciano ${ }^{1}$

RESUMO: Por meio da análise do conto "Pingentes", do livro Malhação do Judas carioca (1976), de João Antônio, e da crônica "Zero grau de Libra", do livro de crônicas Pequenas epifanias (1996; crônica publicada no jornal O Estado de São Paulo em 1986), de Caio Fernando Abreu, procuraremos demonstrar de que maneira cada um dos escritores retrata os marginalizados sociais de duas grandes metrópoles brasileiras, respectivamente Rio de Janeiro e São Paulo.

ABSTRACT: Through the analysis of the short story "Pingentes", from the book Malhação do Judas carioca (1976), written by João Antônio, and the chronicle "Zero grau de Libra", from the book Pequenas epifanias (1996; narrative published in the newspaper O Estado de São Paulo in 1986), by Caio Fernando Abreu, we will seek to demonstrate the way each of the writers portrays the social marginalized individuals from two large Brazilian metropolis, respectively Rio de Janeiro and São Paulo.

PALAVRAS-CHAVE: Estudos comparados; Língua portuguesa; Marginalidade KEYWORDS: Comparative Literature Studies; Portuguese Language; Marginality

Nas palavras do sociólogo polonês Zygmunt Bauman, "as idéias, e as palavras que as transportam mudam de significado quanto mais longe elas viajem - e viajar entre as casas dos consumidores satisfeitos e as moradas dos sem poder é uma travessia de longa distância” ${ }^{2}$. A nosso ver, essa travessia de que fala Bauman aproxima-se muito ao exercício de escrita de João Antônio e Caio Fernando Abreu. Desse modo, pretendemos demonstrar, a partir do estudo comparativo de dois

\footnotetext{
${ }^{1}$ Mestranda em Estudos Comparados de Literaturas de Língua Portuguesa, FFLCHUSP. Pesquisa: Travessias solitárias: um estudo sobre as personagens de João Antônio e Caio Fernando Abreu. E-mail: flaviamerighi@usp.br.

2 BAUMAN, Z. O mal-estar da pós-modernidade. Rio de Janeiro: Jorge Zahar, 1998, p. 42.
} 
textos literários desses autores, em que medida ambos retratam a parcela economicamente marginalizada e oprimida da população brasileira, mais especificamente de São Paulo e do Rio de Janeiro, uma longa e dura travessia ao espaço delimitado desses excluídos sociais.

Os textos analisados neste ensaio são o conto-reportagem "Pingentes", de João Antônio, pertencente ao livro Malhação do Judas carioca (1975) 3, e a crônica "Zero grau de Libra", de Caio Fernando Abreu, do livro de crônicas Pequenas epifanias (1996, porém publicada no jornal O Estado de São Paulo em 1986) ${ }^{4}$.

Nossa opção pela leitura de duas narrativas curtas deve-se ao fato de ser a forma privilegiada por ambos os autores e à sua maior representatividade do cotidiano. O conto e a crônica englobam e potenciam em seu espaço as mais diversas possibilidades de ficção e não só conseguem captar a temática do romance, mas também põem em jogo “(...) os princípios de composição que regem a escrita moderna em busca do texto sintético e do convívio de tons, gêneros e significados" 5 .

Segundo Flávio Aguiar, João Antônio não poderia ser romancista, já que "seu estilo é adequado à forma catastrófica do conto, que conta sem contar, revela pelo que oculta, até o momento final, quando o desenho se completa e o segredo se revela" 6. Tal afirmação também pode ser aplicada ao exercício de escrita de Caio Fernando Abreu, que elege o conto e a crônica jornalística para discutir conflitos sociais, políticos, existências e comportamentais. Bruno Souza Leal esclarecenos que o autor, como seus contemporâneos, "tem a temática urbana, a vivência de uma época à qual se busca incorporar/retrabalhar via literatura o exercício de uma narrativa curta" 7 .

\footnotetext{
3 Malhação do Judas carioca. Rio de Janeiro: Civilização Brasileira, 1975.

${ }^{4}$ Pequenas Epifanias. Porto Alegre: Sulina, 1996.

5 BOSI, A. "Situação e formas do conto brasileiro contemporâneo". In: O conto brasileiro contemporâneo. São Paulo: Cultrix, 1975.

6 Ver: "Evocação de João Antônio ou do purgatório ao inferno". In: João Antônio: Remate de males. Revista do Departamento de Teoria Literária - IEL / UNICAMP. Campinas, 19, 1999, p. 116.

7 Ver: Caio Fernando Abreu, a metrópole e a paixão do estrangeiro: contos, identidade e sexualidade em trânsito. São Paulo: Annablume, 2002.
} 
A escolha do método comparativo para realizar a análise dos textos de João Antônio e Caio Fernando Abreu relaciona-se à necessidade de enfocar e refletir não apenas sobre suas semelhanças, mas também sobre suas diferenças, instauradoras de singularidades literárias e das quais falaremos mais adiante ${ }^{8}$. Como sabemos, tais proximidades podem relacionar-se tanto a fatores externos, como o contexto histórico e político, quanto a fatores internos à obra, como as personagens e o foco narrativo. Assim, à medida que comparamos os textos, refletiremos sobre fenômenos como a modernização conservadora $^{9}$ e o intenso processo de urbanização que ocorreu no Brasil em meados do século XX.

Walter Benjamin, em seu estudo sobre a Paris do Segundo Império (1938), chega a uma representação bastante fiel da modernidade dos anos 1920 e 1930. Apesar de o autor refletir sobre o processo de modernização na Europa, Willi Bolle afirma que "a obra bastante eurocentrada de Benjamin tem tido uma recepção que ultrapassa de longe a esfera da cultura européia” 10. Tanto no Brasil como em grande parte da América Latina, a discussão de seus textos sobre a Modernidade teve início a partir da metade do século XX. Entretanto, perante as diferenças históricas, geográficas e sociais entre Europa e América Latina - mais especificamente Brasil - como se basear nas representações de Benjamin das grandes cidades para esboçar um retrato pertinente de uma metrópole brasileira? ${ }^{11}$ Como afirma Bolle,

\footnotetext{
8 MARQUES, R; BITTENCOURT, G. (orgs.) "Poesia e nacionalidade: a construção da diferença”. In: Limiares Críticos: ensaios sobre literatura comparada. Belo Horizonte: Autêntica, 1998, p. 54.

9 O termo "modernização conservadora" foi utilizado por Norbert Elias e Annie Dymetman para caracterizar a ausência de revolução burguesa na Alemanha, o que culminou na convivência entre a antiga organização política do império alemão e a nova ordem econômica republicana. No Brasil, esse processo ocorreu devido a essa transição rápida de estruturas sociais predominantemente agrárias para sociedades urbanas, o que teve como conseqüência a exclusão social, dentre outras, discutidas por teóricos de diversas áreas, como Florestan Fernandes e Milton Santos.

10 Ver: "Introdução: Walter Benjamin: fisiognomista da metrópole moderna". In: Fisiognomia da metrópole moderna. São Paulo: Editora da Universidade de São Paulo; FAPESP, 2000.

${ }^{11}$ Idem, p. 33.
} 
o primeiro de seus quadros urbanos, o ensaio "Nápoles" (...), aponta significativamente em direção ao Sul. Aquela imagem apenas esboçada de caos, miséria e crime - a história se encarregou de completá-la em forma de uma ampliação gigantesca: a partir de meados do século $\mathrm{XX}$, um processo de crescimento explosivo, na Ásia, América Latina e África fez surgirem maiores e mais problemáticas aglomerações na história da humanidade. O discurso da modernização ficou de ponta cabeça, e os desdobramentos futuros são incalculáveis ${ }^{12}$.

Assim, no Brasil, a noção de uma consciência urbana moderna nasceu simultaneamente à metrópole moderna no início do século XX, na cidade de São Paulo, que foi pela primeira vez protagonista em Paulicéia Desvairada (1922), de Mário de Andrade, obra simultânea à Semana de Arte Moderna, marco inicial do Movimento Modernista brasileiro. Desde então, a metrópole e seu poder de transformação das estruturas sociais acentua-se cada vez mais.

Florestan Fernandes, em um ensaio escrito em 1959, reflete sobre as transformações sociais na cidade de São Paulo, afirmando que correspondiam a "fenômenos sociais mal conhecidos" 13. Segundo o sociólogo, São Paulo encontra-se em uma posição geográfica favorável à sua expansão, o que a torna "um centro natural de confluência das atividades de várias regiões prósperas do Estado de São Paulo” 14. Um processo semelhante ocorria, em meados do século XX, com outras capitais brasileiras, como o Rio de Janeiro.

Todavia, Fernandes considerava as condições para o crescimento de São Paulo negativas e até impróprias ao surto urbano. Com o aumento intensivo da população, a industrialização e a urbanização, diversos problemas vieram à tona, como a alteração da configuração ecológica e, principalmente, as diferenças sociais. Dentre outros fatores, a distribuição desigual da renda evidenciou os drásticos contrastes sociais. Nas palavras do autor,

\footnotetext{
12 Ibidem, p. 33.

13 Ver: "O homem e a cidade metrópole". In: Educação e Ciências Sociais. Rio de Janeiro: Centro Brasileiro de Pesquisas Educacionais, Agosto de 1959. Ano IV, vol. 5, $\mathrm{n}^{\circ} 11$, p. 24.

${ }^{14}$ Idem, p. 24.
} 
A conseqüência grave dessa situação possui duas polarizações distintas. De um lado, ela favorece a coexistência do luxo com a miséria nas suas formas mais extremas. De curto, ela reduz, consideravelmente, a influência dinâmica das tensões e conflitos nas relações das classes sociais. Tensões e conflitos perdem muito do seu caráter social construtivo, afetando mais as margens da luta pela subsistência e da sobrevivência que a reconstrução social e a democratização das formas de participação social da cultura, da riqueza e do poder (destaque meu) ${ }^{15}$.

Portanto, a partir de Mário de Andrade e Oswald de Andrade, a literatura brasileira ganha cada vez mais representantes dessa crescente urbanização, como Rubem Fonseca, Plínio Marcos, Ignácio de Loyola Brandão, João Antônio, Caio Fernando Abreu, dentre muitos outros. De modo geral, os escritores que pintam a metrópole moderna também refletem sobre sua miséria e desigualdade social, a extrema injustiça que sofrem os mais pobres, a degradação humana, a crise de identidade e a ausência de esperança de que algo se transforme.

João Antônio, no conto-reportagem "Pingentes", "persegue os escombros da modernização" 16 em um Rio de Janeiro que não pára de crescer à custa da exclusão social. Através dos olhos dos marginalizados, o autor denuncia a situação da parcela pobre da população da capital carioca, que se dependura nos trens da Central do Brasil a fim de deslocar-se do Rio Abandonado, como chama o autor, aos bairros mais centrais da cidade, onde há mais chances de se encontrar trabalho: "Um pingente como Jaime dos Santos, vinte anos, ganhando quatrocentos e vinte cruzeiros por mês no comércio da Rua Alfândega, para pegar às oito no trabalho acorda às cinco e apanha o trem das sete em Cascadura" 17.

\footnotetext{
15 Ibidem, p. 32.

16 CHIAPPINI, Lígia. "O Brasil de João Antônio e a sinuca dos pingentes". In: CHIAPPINI, L., DIMAS, A., e ZILLY, B. (orgs.). Brasil, país do passado? São Paulo: Editora da Universidade de São Paulo; Boitempo, 2000, p. 159.

17 Malhação do Judas carioca. Rio de Janeiro: Civilização Brasileira, 1976, p. 27.
} 
Logo no início do conto, João Antônio lembra-nos que, apesar de haver pingentes desde a década de 1920 nos trens da Central, os escritores da época estavam preocupados com "beletrismos e parnasianismos" 18, com exceção de Lima Barreto, o "mulato pobre que não passou de funcionário miúdo do Ministério da Guerra” 19 e que denunciava as injustiças sociais em seu romance Clara dos Anjos.

Passados quase sessenta anos até a publicação de Malhação do Judas carioca, em 1975, João Antônio é um dos poucos escritores brasileiros que retratam a realidade do morador do subúrbio do Rio de Janeiro, passageiro da Central do Brasil, que só vira notícia quando é pingente, e "pingente morto, desastrado e causador de desastres" 20. Afora isso, são esquecidos pela mídia, pelos governantes municipais e pelas campanhas de reeducação do povo.

Na maioria das vezes, obrigado a viajar dependurado, o pingente é visto exclusivamente como irresponsável por aqueles que nunca andaram nos trens da Central. O português Antônio Mendes, atendente do balcão de um dos botequins da estação, expõe sua opinião sobre o fato:

- Olhe aí. Depois tem que haver desastre e morte, não é? Agora não é nada, vai ver quando vier o trem. Tem gente que sobre e desce pelas janelas, tem gente que viaja em cima do vagão, tem gente que vem sentada na janela e a maioria vem urrando ${ }^{21}$.

Também com a perspectiva de quem não conhece de perto a situação, a socióloga procura explicá-la por meio de um discurso psicologizante ${ }^{22}$, que centra a causa do problema na desumanização dos passageiros devido aos horários, o que resulta na perda de sua

\footnotetext{
18 Idem, p. 24.

19 Ibidem, p. 24.

20 Ibidem, p. 24.

${ }^{21}$ Ibidem, p. 26.

22 De acordo com Baptista, tais discursos são característicos dos "amoladores de facas" e têm em comum "a presença camuflada do ato genocida". São discursos autoritários que geram o preconceito, já que não levam em conta a real situação do outro e suas necessidades. Ver: BAPTISTA, L. A. "A solidão e a inércia do discurso psi" e "A atriz , o padre e a psicanalista". In: A cidade dos sábios. São Paulo: Summus, 1999, p. 33-49.
} 
individualidade dentro da multidão da metrópole e, conseqüentemente, na tentativa de enfrentar a máquina, a fim de readquirir a sua humanidade. Porém, João Antônio chama-nos a atenção para a real causa do problema por meio de outro discurso, o da empregada doméstica Maria Teresa Conceição Martins, representante dos moradores do subúrbio carioca: "- A gente pega o trem da Central porque custa cinqüenta centavos. Se eu fosse pegar ônibus, só de Cascadura até o Passeio Público gastava oitenta. Manjou? É aquela de pobre não luta, peleja” ${ }^{23}$.

Nesse conto de João Antônio, a socióloga sem nome e qualquer referência institucional tem menos voz do que a trabalhadora Maria Teresa, que sai de Cascadura todos os dias para trabalhar em Copacabana. No entanto, o autor evidencia o desinteresse geral à situação dos pingentes questionando quem será responsável pelos acidentes e mortes nos trens. Para João Antônio, ainda que a Rede Ferroviária oferecesse seus advogados, poucos receberiam indenização, já que os próprios passageiros não pingentes reiteram que ninguém viaja do lado de fora do trem quando chove.

O autor finaliza seu conto evocando novamente Lima Barreto: "Mas pela visão de Lima Barreto, as coisas talvez ficassem assim: toda a Zona Norte, o chamado Rio Esquecido, não tem nenhuma representatividade política, tudo é feito e dirigido para a Zona Sul da cidade" ${ }^{24}$. É fato que, ainda em 1975, houve a realização do primeiro teste do trem "anti-pingente" e que atualmente a minoria da população do Rio de Janeiro, moradora dos bairros mais ricos, continua sendo a mais privilegiada, ao contrário das que vivem no subúrbio. Essas, o escritor João Antônio, mais de cinqüenta anos depois de Lima Barreto, chamava de sobreviventes.

A cidade de São Paulo vista pelos olhos de Caio Fernando Abreu não é muito diferente do Rio de Janeiro de João Antônio. Na crônica "Zero grau de Libra", o autor evidencia os marginalizados da metrópole 
paulista na medida em que pede “(...) a isso que chamamos de Deus um olho bom sobre o planeta Terra, e especialmente sobre a cidade de São Paulo" 25.

Na astrologia, zero grau de Libra corresponde à travessia do Sol a esse signo, dando início ao outono no Hemisfério Norte e à primavera no Hemisfério Sul. Essa passagem do Sol ocorre por volta do dia 23 de setembro, dia anterior à publicação da crônica de Abreu no jornal $O$ Estado de São Paulo. Segundo ele, o signo de Libra "é o outro (quando se olha e se vê o outro, e de alguma forma tenta-se entrar em alguma espécie de harmonia com ele)” ${ }^{26}$. Ainda, é o signo regido pelo planeta Vênus, que representa o amor.

No "Zero grau de Libra”, o autor decide pedir a Deus - "mesmo em vão, porque pedir não só é bom, mas às vezes é o que se pode fazer quando tudo vai mal" 27 - tanto um olho quente sobre o mendigo gelado embaixo da marquise do cine Majestic quanto sobre a noiva que se encontra mais acima. Aponta, portanto, dois diferentes retratos da sociedade: aquele que caminha fora do círculo de normas e condutas sociais e o que representa uma das tantas demandas dos que estão inseridos na "roda da vida" ${ }^{28}$. Desse modo, Abreu esboça, ao longo de sua crônica, a condição de determinados tipos sociais típicos da classe média sufocada por percalços menos evidentes, mas nem por isso menos cruéis, e finaliza enumerando os tipos sociais que se encontram totalmente à margem da sociedade.

No próximo parágrafo do texto, o autor faz uma solicitação bemhumorada: "Eu queria um olho bom de Deus derramado sobre as loiras oxigenadas, falsíssimas, o olho cúmplice de Deus sobre as jóias douradas, as cores vibrantes" ${ }^{29}$. A seguir, pede seu olhar piedoso sobre os casais que comem pizza com refrigerante, mas não conseguem se defrontar, bem como um olhar amoroso sobre todos aqueles "que já

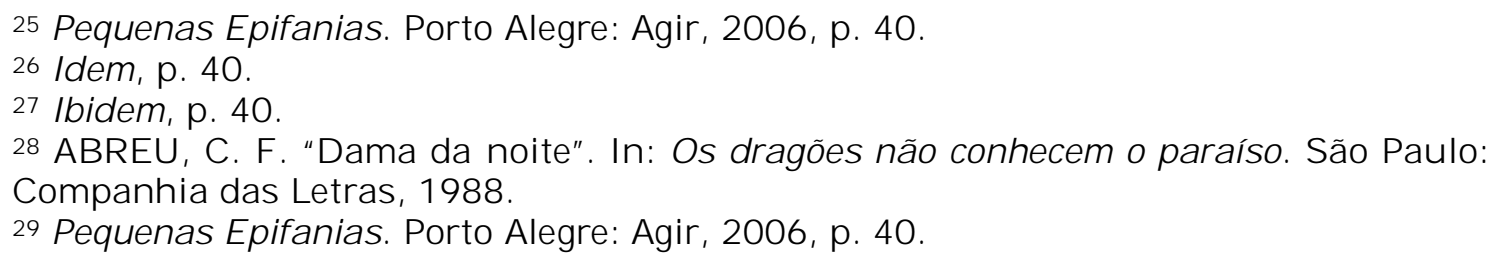


tiveram um amor, e de alguma forma insana esperam a volta dele: que os telefones toquem, que as cartas finalmente cheguem" 30 .

Trazendo à luz os problemas da metrópole moderna, Caio Fernando Abreu chama a atenção de Deus às crianças presas nos edifícios, que brincam em playgrounds de cimento, e ao "cotidiano dos funcionários públicos ou daqueles que, como funcionários públicos, cruzam-se em corredores sem ao menos se verem - nesses lugares onde um ser humano vai-se tornando aos poucos tão humano quanto uma mesa”. ${ }^{31}$ A mesma atenção divina merecem a cidade suja, as "garotas performáticas" 32 que trabalham como garçonetes para pagarem o aluguel, e aquele que, nas altas horas da noite, liga para o CVV ${ }^{33}$. A solidão do rapaz que repete dez vezes Moon Over Bourbon Street e chora também é lembrada na crônica.

A multidão sob a marquise do Mappin protegendo-se da chuva de granizo, o taxista que não tem mais esperança; o pintor que gostaria de pintar, mas precisa sobreviver na agência de publicidade, e o escritor que queria ganhar mais por seu texto: tais exemplos refletem a luta pela sobrevivência em uma metrópole marcada pela indiferença e, conseqüentemente, pelo anonimato ${ }^{34}$.

O autor refere-se, ainda, aos grupos de terapia, um advento comum da modernidade e mais freqüente nas grandes cidades, e completa pedindo o perdão de Deus àqueles que, além de marginalizados, são alvos de preconceito:

(...) deita teu perdão sobre os grupos de terapia e suas elaborações sobre a vida, sobre as moças desempregadas em seus pequenos apartamentos na Bela Vista, sobre os homossexuais tontos de amor não dado, sobre as prostitutas

\footnotetext{
30 Idem, p. 41.

31 Ibidem, p. 41.

32 Ibidem, p. 41.

33 Em 1962, foi fundado, na cidade de São Paulo, o Centro de Valorização da Vida (CVV) devido ao aumento do suicídio nas grandes metrópoles. O objetivo do programa é a prevenção do suicídio e o apoio emocional às pessoas angustiadas. Ver: http://www.cvv.com.br/ .

34 Ver: SIMMEL, G. "A metrópole e a vida mental". In: VELHO, O. O fenômeno urbano. Rio de Janeiro: Zahar, 1976, p. 12-25.
} 
seminuas, sobre os travestis da Republica do Libano, sobre os porteiros de prédios comendo sua comida fria nas ruas dos Jardins (grifo meu) ${ }^{35}$.

A perspectiva melancólica torna-se evidente quando Abreu pede um olhar divino sobre todos aqueles que não deram certo - porque, segundo ele, é sujo dar certo no esquema em que vivemos - e sobre todos que continuam tentando, mesmo sem motivo: "sobre esses que sobrevivem a cada dia ao naufrágio de uma por uma das ilusões" (destaque meu) ${ }^{36}$.

Ao fim, o autor suplica não mais um olho amoroso, mas o olhar mais impiedoso de Deus sobre "as antas poderosas, ávidas de matar o sonho alheio" 37. Revela, portanto, seu desejo de que se faça justiça contra aqueles que subjugam e oprimem os mais desfavorecidos. A balança de Libra é também a da Justiça, convocada para que use sua espada sem piedade; porém, com os que se esforçam e sangram todos os dias sem ceder, que Deus seja complacente e envie seu Sol mais luminoso. No parágrafo final, o último pedido do autor resgata os demais e fecha a crônica: "Sorri, abençoa nossa amorosa miséria atarantada" 38 .

\section{Olhares cruzados: a presença da marginalidade}

As reflexões de João Antônio e Caio Fernando Abreu sobre as conseqüências da modernização não estavam isoladas. No entanto, o que nos interessa é o fato de ambos abordarem temáticas bastante semelhantes e retratarem a parcela marginalizada da população, utilizando-se de diferentes linguagens. O primeiro busca de maneira consciente observar o mundo como o lúmpen o vê e, na maioria das vezes, alcança esse propósito ${ }^{39}$. O segundo possui um tom mais lírico e

\footnotetext{
35 Pequenas Epifanias. Porto Alegre: Agir, 2006, p. 41.

36 Idem, p. 42.

37 Ibidem, p. 42.

38 Ibidem, p. 42.

39 CHIAPPINI, Lígia. "O Brasil de João Antônio e a sinuca dos pingentes". In:
} 
confessional, mas, na maior parte de seus contos, retrabalha a linguagem literária a fim de aproximá-la às suas personagens, geralmente urbanas, marginalizadas e desassossegadas existencialmente.

Ainda, João Antônio e Caio Fernando Abreu têm em comum a forte ligação com o jornalismo, assim como grande parte dos escritores que surgem entre as décadas de 1960 e 1980, dentre eles Ferreira Gullar, Carlinhos Oliveira, Ivan Angelo, Roberto Drummond, Ignácio de Loyola Brandão e Luiz Vilela. A ocupação de jornalista instaura-os como observadores do cotidiano da metrópole, que se torna quase uma personagem tanto em suas crônicas quanto em seus contos.

Assim, João Antônio e Abreu tecem ficções diferenciadas do ponto de vista estético, mas apresentam uma postura de resistência às conseqüências negativas da modernização, o que aproxima seus projetos literários do ponto de vista ético.

Nos contos aqui analisados, bem como em grande parte da obra dos autores, é evidente a presença de uma perspectiva melancólica relacionada às mudanças sociais. João Antônio sabe que a população dos bairros mais pobres do Rio de Janeiro nunca terá a mesma atenção da população residente na Zona Sul, sete vezes menor do que aquela; Abreu pede a um Deus de que duvida da existência um pouco de atenção aos sobreviventes do naufrágio das ilusões, perdidas cotidianamente.

Leandro Konder esclarece-nos que as principais contradições da cidade são, em grande parte, as contradições da sociedade ${ }^{40}$. Ou seja, a metrópole acentua os contrastes e os conflitos sociais, contrapondo cotidianamente "os pólos da riqueza e da pobreza" ${ }^{41}$, o que intensifica o medo entre as camadas sociais privilegiadas e a frustração entre os marginalizados. Alvos de experiências violentas, os habitantes dos

CHIAPPINI, L., DIMAS, A., e ZILLY, B. (orgs.). Brasil, país do passado? São Paulo: Editora da Universidade de São Paulo; Boitempo, 2000, p. 160.

40 Ver: "O homem burguês na sua cidade". In: Os sofrimentos do "homem burguês". São Paulo: SENAC, 2000, p. 65.

41 Idem, p. 65. 
grandes centros urbanos acabam se tornando - utilizando o termo do próprio autor - "anestesiados", mergulhando em um estado de espírito profundamente melancólico. Dessa forma, a partir do momento em que o Brasil começa a se modernizar, acentua-se o contraste progressoatraso e o conflito campo-cidade, aumentando o desamparo das populações marginalizadas e, por conseguinte, seu pessimismo 42 .

Outro traço em comum nos contos é referente à situação dos marginalizados sociais. Os pingentes de João Antônio não se dependuram apenas nos trens: são pingentes da cidade. Tratam-se, segundo o autor, de "sobreviventes urbanos" 43, nunca estáveis ou tranqüilos, correspondentes aos tipos sociais referidos por Caio Fernando Abreu, aqueles que de alguma forma não deram certo ${ }^{44}$. Os grupos e indivíduos retratados em ambos os textos lutam pela sobrevivência, seja pendurando-se nos trens para poder trabalhar, seja despindo-se nas ruas de São Paulo.

Abreu retoma o tema da prostituição por meio da personagem Dama da noite, do conto homônimo ${ }^{45}$. No entanto, assim como ocorre em outros textos do autor ${ }^{46}$, a personagem em questão é uma incógnita até as últimas linhas do conto. Poderíamos classificá-la como prostituta, já que o próprio título do conto nos leva a interpretá-la dessa forma: dama-da-noite, além do nome da flor que recolhe seu perfume com a luz do dia, é uma forma antiga de se chamar essas mulheres. No entanto, sua solidão e seu medo da luz do sol aproximam-na mais do travesti, estrangeiro de corpo e identidade, à margem da sociedade. Fica claro, ao fim da leitura do conto de Caio Fernando Abreu, que a sexualidade da Dama é indefinível e, ainda, que o autor não delegava tanta importância a essa definição, já que é evidente que se trata, independentemente da mesma, de uma personagem marginalizada.

\footnotetext{
42 SCLIAR, Moacyr. "A melancolia chega ao trópico". In: Saturno nos trópicos: a melancolia européia chega ao Brasil. São Paulo: Companhia das Letras, 2003, p. 203.

43 Malhação do Judas carioca. Rio de Janeiro: Civilização Brasileira, 1976, p. 25.

44 Pequenas Epifanias. Porto Alegre: Agir, 2006, p. 41.

45 In: Os dragões não conhecem o paraíso. São Paulo: Companhia das Letras, 1988.

46 Ver: “Aqueles dois”. In: Morangos mofados. São Paulo: Brasiliense, 1982.
} 
Outro traço relevante nos textos de João Antônio e Abreu é a recriação da linguagem, presente em toda a obra do primeiro e em grande parte dos contos do segundo, especialmente naqueles em que se destacam personagens marginalizadas. Referente aos contos em questão, João Antônio busca retrabalhar a linguagem literária a partir da fala cotidiana, o que resulta em uma escrita marcada por características próprias da oralidade; ainda, utiliza-se do depoimento para dar voz aos marginalizados, como pudemos observar em nossa análise. Abreu, por sua vez, opta por uma narrativa mais leve e com um acento lírico, o que a aproxima mais da oração.

Desse modo, os textos aqui analisados relacionam-se, pois estão carregados de crítica social e põem em evidência os excluídos sociais. Tal característica atesta a postura de resistência dos autores e torna relevante a discussão de seus projetos literários, comprometidos em denunciar a desigualdade social e questionar a ordem estabelecida. João Antônio retrata os merdunchos ${ }^{47}$, os pingentes, os malandros e os marginalizados com condições mínimas de sobrevivência na metrópole, enquanto Caio Fernando Abreu expõe os conflitos do sujeito com relação à sua identidade e a seu cotidiano nas grandes cidades, bem como seu lugar à margem, que o exclui da "roda da vida".

\section{Referências bibliográficas}

AGUIAR, F. Evocação de João Antônio ou do purgatório ao inferno. In João Antônio: Remate de males. Revista do Departamento de Teoria Literária — IEL / UNICAMP; Campinas; 19. 1999.

ABREU, C. F. Dama da noite. In Os dragões não conhecem o paraíso. São Paulo: Companhia das Letras, 1988. . Pequenas Epifanias. Porto Alegre: Agir, 2006.

ANTÔNIO, J. Malhação do Judas carioca. Rio de Janeiro: Civilização Brasileira, 1976.

. Casa de Loucos. Rio de Janeiro: Civilização Brasileira, 1976.

BAPTISTA, L. A. A solidão e a inércia do discurso psi e A atriz, o padre e a psicanalista. In A cidade dos sábios. São Paulo: Summus, 1999.

BAUMAN, Z. O mal-estar da pós-modernidade. Rio de Janeiro: Jorge Zahar, 1998, p. 42.

47 ANTÔNIO, João. Casa de Loucos. Rio de Janeiro: Civilização Brasileira, 1976, p. 55. 
BERMAN, M. Tudo que é sólido desmancha no ar: a aventura da modernidade. São Paulo: Companhia das Letras, 2007.

BOLLE, W. Introdução: Walter Benjamin: fisiognomista da metrópole moderna. In Fisiognomia da metrópole moderna. São Paulo: Editora da Universidade de São Paulo; FAPESP, 2000.

BOSI, A. Situação e formas do conto brasileiro contemporâneo. In $O$ conto brasileiro contemporâneo. São Paulo: Cultrix, 1975.

CANDIDO, A. Na noite enxovalhada. In João Antônio: Remate de males. Revista do Departamento de Teoria Literária - IEL / UNICAMP; Campinas: 19. 1999.

CHIAPPINI, Lígia. O Brasil de João Antônio e a sinuca dos pingentes. In CHIAPPINI, L., DIMAS, A., e ZILLY, B. (orgs.). Brasil, país do passado? São Paulo: Editora da Universidade de São Paulo: Boitempo, 2000.

FERNANDES, F. O homem e a cidade metrópole. In Educação e Ciências Sociais; Rio de Janeiro; Centro Brasileiro de Pesquisas Educacionais; 5(11); ago. 1959 .

KONDER, L. O homem burguês na sua cidade. In Os sofrimentos do "homem burguês". São Paulo: SENAC, 2000.

LEAL, B. S. Caio Fernando Abreu, a metrópole e a paixão do estrangeiro: contos, identidade e sexualidade em trânsito. São Paulo: Annablume, 2002.

MARQUES, R. Poesia e nacionalidade: a construção da diferença. In MARQUES, R.; BITTENCOURT, G. N. (orgs.). Limiares Criticos: ensaios sobre literatura comparada. Belo Horizonte: Autêntica, 1998.

SCLIAR, Moacyr. A melancolia chega ao trópico. In Saturno nos trópicos: a melancolia européia chega ao Brasil. São Paulo: Companhia das Letras, 2003.

SIMMEL, G. A metrópole e a vida mental. In VELHO, O. O fenômeno urbano. Rio de Janeiro: Zahar, 1976. 